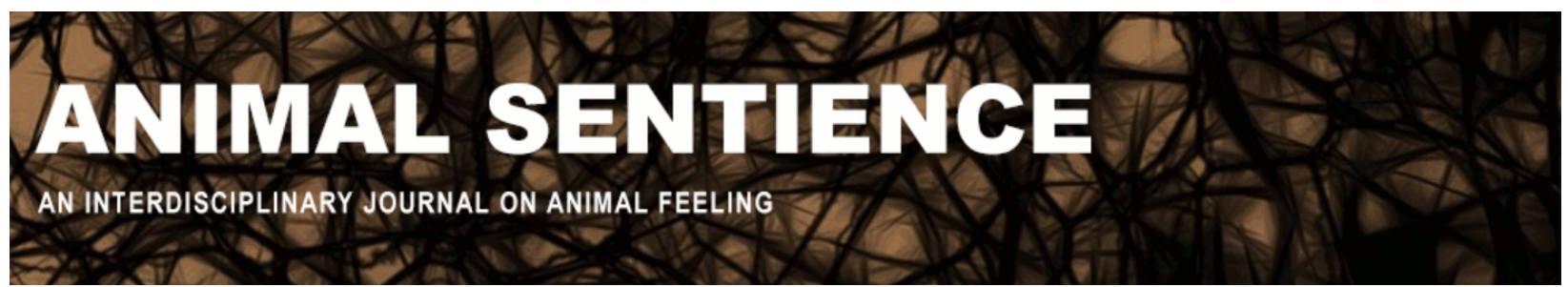

Sammarco, Andrea L. (2016) Is humanitarianism recent?. Animal Sentience 5(10) DOI: $10.51291 / 2377-7478.1002$

Date of submission: 2015-03-03

Date of acceptance: 2015-12-13

(c) (i)




\title{
Is humanitarianism recent?
}

Commentary on Broom on Animal Welfare

\author{
Andrea L. Sammarco \\ Attorney, Sammarco Law Firm
}

\begin{abstract}
Although there is the need for textbooks in this field, the literary style of Broom's Sentience and Animal Welfare detracts from the readability of the book. The author attempts with mixed success to define the field and differing opinions regarding the definitions of "sentience" and "animal welfare," but makes a number of questionable assumptions concerning the history of the subject area.
\end{abstract}

\begin{abstract}
Andrea L. Sammarco alsammarco18@gmail.com is an attorney and New York State licensed wildlife rehabilitator who has volunteered for numerous charitable organizations, including the Bless the Beasts Foundation, the Erie County SPCA Wildlife Department and others, and served as in-house counsel for People for the Ethical Treatment of Animals. http://www.sammarcolaw.com/aboutus.html
\end{abstract}

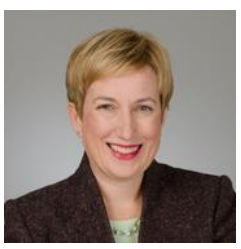

In Sentience and Animal Welfare, Broom (2014) does an admirable job negotiating the literary no man's land of college textbooks on sentience and animal welfare. The offerings in this category are far from abundant, but the market is bound to increase as veterinary colleges, philosophy departments, and academia continue to embrace the premise that such a subject is worthy of more serious attention and respect than previously thought. While increasing the choices available in the classroom has its benefits, Broom's style of writing detracts from the readability and pleasure one might have experienced from subject matter as fascinating as this.

The phrase "animal welfare" itself is subject to such a diverse array of interpretations as to generate much exposition by Broom in the opening chapters of the book: what it is and is not, what it used to be (i.e., a utilitarian tool used by farmers and scientists to coax maximum profitability from their research subjects or herds), how it differs from "animal rights," and by what means one may incorporate "animal feelings" into the definition. The mere act of parsing out the book's subject matter required me to consult the glossary presciently included by Broom in the preface.

It was perhaps because of the dearth of prior attention to the subject that Broom repeatedly self-references previous works authored or co-authored by him. I found this aspect distracting and argumentative, particularly when coupled with sidetracks into defenses of his previous writings.

In addition, Broom's insistence on portraying the concept of animal welfare and concern for nonhuman animals as a progressive and evolving continuum in human societies struck me as 
somewhat myopic. We cannot say with complete confidence what primitive societies long ago thought about the subject and there certainly is ample evidence that human beings have attributed thoughts, feelings, emotion, and sentient status to nonhuman animals at various points throughout our existence. One need only consult Hinduism for examples of animal reverence and respect that date back many centuries. In this context, it is hard to accept at face value Broom's assertion that human opinion has consistently expanded over time in "welleducated societies" to encompass nonhuman animals within the scope of those considered sentient.

Finally, I found Broom's observations, in particular his postulations concerning "rights-oriented" versus "obligations-oriented" precepts toward animals, to be compelling and on point. They should help guide the discussion into fruitful areas of inquiry, advancing the message of compassion and consideration for those who share this earth with us.

\section{References}

Broom, D.M. (2014). Sentience and animal welfare. Wallingford: CABI. 